\title{
Evidences in Scientific Knowledge Management of Biotechnology in Brazil
}

\author{
Maria de Fátima Ebole Santana \\ Polytechnic School of Health Joaquim Venancio (EPSJV)/ Oswaldo Cruz Foundation (Fiocruz) 4365 \\ Brasil Ave, Manguinhos, Rio de Janeiro, RJ, Brazil, Zipcode: 21045-900 \\ Nei Pereira Jr. \\ Chemical School/ Federal University of Rio de Janeiro (UFRJ) \\ 149Athos da Silveira Ramos Ave, Ilha do Fundão, Rio de Janeiro, RJ, Brasil. Zipcode: 21949-900
}

\section{Adelaide Maria de Souza Antunes}

National Institute of Industrial Property (INPI)

7 Praça Mauá, Downtown, Rio de Janeiro, RJ, Brasil. Zipcode: 20081-240

\section{Marcio Sacramento de Oliveira}

Polytechnic School of Health Joaquim Venancio (EPSJV)/ Oswaldo Cruz Foundation (Fiocruz) 4365

Brasil Ave, Manguinhos, Rio de Janeiro, RJ, Brazil, Zipcode: 21045-900

\begin{abstract}
This paper presents a study on scientific knowledge management of Biotechnology area through analysis of scientific Biotechnology trends in Brazil, providing an overview of the science profile as well as regional development and its relation to issues of topics based on the analysis of scientific publications for the period of last 10 years. Given these promising prospects, the monitoring and searching of scientific advances and trends in this area of knowledge have become essential for searching opportunities in $R \& D$ and also for potential innovations and business opportunities, both in developed countries as well as in countries of emerging economies such as Brazil. The survey was accomplished in database Web of Science using 60 terms selected in Biotechnology area and 72,187 documents has been organized. Scientific indicators were produced using data/text mining tools. It was possible to find a greater number of scientific publications in areas such as Biochemistry \& Molecular Biology and Genetics \& Heredity. Results pointed out The USA as the main foreign partner-country of scientific publications followed by UK, France and Germany. It was possible to verify cooperation network with others Latin American countries.
\end{abstract}

Keywords: Management, Scientific Knowledge, Innovation, Biotechnology, Brazil.

Abbreviations:

CNPq: National Research Council

MCT: Brazil Ministry of Science, Technology and Innovation

\section{INTRODUCTION}

Technological advance has been the dominant driving force in modern society leading to a widespread diffusion of products from the rational activity as well as of scientific, technological and administrative sources, which in turn requires new types of management [1].

This technological progress has proclaimed a new paradigm based on the development of a set of intensive knowledge on scientific technologies. These technologies represent a range of applications of scientific discoveries, whose core is to develop an increasing competence to manage information and knowledge, as well as their direct applications in the production process. The intangibles such as knowledge (know how), patents and intellectual capital become increasing value strategic variables to occupy the center of contemporary forms of capital accumulation.

Biotechnology, as a highly science-based sector, is one of the most knowledge-intensive forms of activity in the contemporary economy. Its emergence is expected to have a major impact on regional 
and national economies, both directly and indirectly. The production of biotechnology products represents a relatively new and significant growth phenomenon on its own. Over the long run, the growth potential associated with the wider diffusion and use of biotechnology products and processes, and their convergence with information technologies, nanotechnologies and other applied sciences, is probably even greater [2].

In this context, Biotechnology is considered a key "future bearing technology" and its applications have contributed to the structuring of new economic and social systems [3]. In this sense, Biotechnology appears to have the characteristics of a core technology, with the potential to underpin a new techno economic paradigm.

Given this perspective, the monitoring and searching of scientific advances and trends in this area of knowledge have become essential for searching opportunities in Research and Development (R\&D) and also for potential innovations and business opportunities, both in developed countries as well as in countries of emerging economies such as Brazil. Since long time, Brazil has tried to develop national capacities in science and technology that allow a better optimization and application of scientific resources and economics and that can generate technological products based on nationally developed Biotechnology [4], like improving its infrastructure of scientific laboratories, more participation in networks experts, training of human resources and others actions.

In this scenario, in order to propose world wild profile of scientific knowledge management in Biotechnology in Brazil, this paper aims to present science trends for this area mapped out through a set of variables such as the identification of the actors involved as well as the international partnerships and the major areas using for this analysis all Brazilian scientific publications of international dissemination for the period of 2004 to 2014.

\section{METHODOLOGY AND RECOVERY DOCUMENTS}

\subsection{Database}

The research was based on the selection of scientific publications collected in ISI/Web of Knowledge

${ }^{\mathrm{SM}}$ database. It is a reliable platform of bibliographic data and is used internationally as reference for the generation of indicators of S\&T and Innovation. ISI/Web of Science ${ }^{\circledR}$ was chosen because it is considered internationally as one of most wide multi-disciplinary scientific database and have strict quality criteria adopted by Thompson Scientific Information, which is responsible institution for its creation, maintenance and data entry.

\subsection{Strategies for Recovery Documents}

For recovery of significant and coherent set of publications that allow an analysis of the scientific production in the Biotechnology area was the elaboration of a complex search expression, consisting by a large of set selected and tested keywords.

For the analysis results in an accurate overview of the subject, ideally, the "search expression" must promote the recovery of all relevant publications on the subject present in the database, and at the same time, exclude non-publications relevant. However, such situation is difficult to achieve since the multi-disciplinary issues receive contributions from several areas of knowledge.

At first, we tried to develop search strategies in the mode "ISI - General Search", using keywords from the available literature and descriptors present on the Platform-Lattes/CNPq-Brazil and Portal Innovation/MCT-Brazil related to research groups and ongoing research in the Biotechnology area. These search expressions were just an exploratory character, that is, serve as a basis for elaborate more refined expressions and evaluate how the area is organized into database [5].A selection from bibliographic references was also used.

In order to achieve the purpose of mining scientific production on Biotechnology in Brazil over a 10 years period (2004-2014), 60 distinct descriptors (Table 1) were used, selected by experts in Biotechnology area interviewed and research groups in Biotechnology area sought in the base Plataforma Lattes CNPq-Brazil and Portal Innovation/MCT-Brazil. From experiences before, we found that the best way to do this recovery would be a combination of different expressions. For this, we used the advanced search mode of ISI/Web of Science, the Advanced Search. Once defined the strategy, we used all these keywords, and various search expression and yours combinations in the database ISI/Web of Science only looking for indexed publication using document types "article". To 
analyze the themes of scientific publications with international dissemination the fields "Title, Summary and Keyword" were used [6].

Table1. Biotechnology Related Terms used to Search Articles in database ISI/ Web of Science.

\begin{tabular}{|l|l|l|l|}
\hline Antisense & Biomaterial & Proteins Engineering & GMO \\
\hline Recombinant Antigen & Biopolymer & Genetic Engineering & Protein \\
\hline Biodiversity & Bioprocess & Metabolic & Recombinant Protein \\
\hline Biocatalyst & Bioprospection & Molecular Engineering & Proteome \\
\hline Biofuel & Bioreactor & Gene Expression & Proteomic \\
\hline Bioeconomy & Bioremediation & Pharmacogenomics & PCR \\
\hline Bioengineering & Biosensor & Phytoremediation & RNA \\
\hline Bioethics & Biosorption & Gene & Microarray DNA \\
\hline Biofiltration & Biosurfactant & Genetic & Microarray RNA \\
\hline Bioindustry & Biosulfurization & Genome & Transcriptome \\
\hline Bioinformatics & Biotechnology & Genomic & Transgenic \\
\hline Biolixiviation & Stemcells & Microbiota & CellularTherapy \\
\hline Computational Biology & Cloning & Biology Modelling & Gene Therapy \\
\hline Biome & T Cells & Nanobiotechnology & Molecular Therapy \\
\hline Biomass & DNA & Peptide & Vaccine \\
\hline
\end{tabular}

\subsection{Processing of Information}

The processing of information from articles retrieved was performed using the software VantagePoint ${ }^{\circledR}$ as a tool for text and data mining to expand and enrich the results. This tool of information management allows you to present correlations of different variables of interest. It also allows you to identify Who, What, When and Where, helping us clarify relationships and find critical patterns, among other possibilities.

For visualization of the data, we used the software VOSviewer®. It is a recent free software for the representation and analysis of information, which appears as an alternative to the traditional techniques of multidimensional representation and network display. VOSviewer ${ }^{\circledR}$ combines visualization and clustering techniques, favoring analysis while bypassing unnecessary technical complications. This type of map is especially useful for detecting the main nuclei of interaction of a domain. VOSviewer® is based on multidimensional scaling for the spatial distribution of information. So using that was possible view maps of collaboration between institutions, countries and Keywords [7].

\subsection{Data/Text Mining Tools and Resources}

After this step, data/text mining tools and resources were used to generate macro-indicators providing a holistic overview of the scientific production on Biotechnology in Brazil, raising the main issues:

- A total number of articles published per year (2004/2014) and the tendency to publish the most frequently used terms on Biotechnology;

- Key areas of knowledge and the number of articles published on used terms;

- Major journals that institutions often publish their articles using the most frequent terms on Biotechnology;

- Number of papers published by institutions and countries in order to identify partnership networks.

- The trends for Biotechnology were mapped out through a set of variables such as the identification of the actors involved as well as the institutional partnerships and networking.

\section{RESULTS AND DISCUSSIONS}

\subsection{Analysis of Results and Co-words Networks}

With regard to the scientific literature on Biotechnology for the period between 2004 and 2014, it was retrieved 72,185 documents containing terms selected by experts in the fields of title, abstract and keywords, and 48,979 documents where Brazil as the home country ( $1^{\text {st }}$ author). The Figure 1 shown the evolution of publication number in Biotechnology area since 2004. 


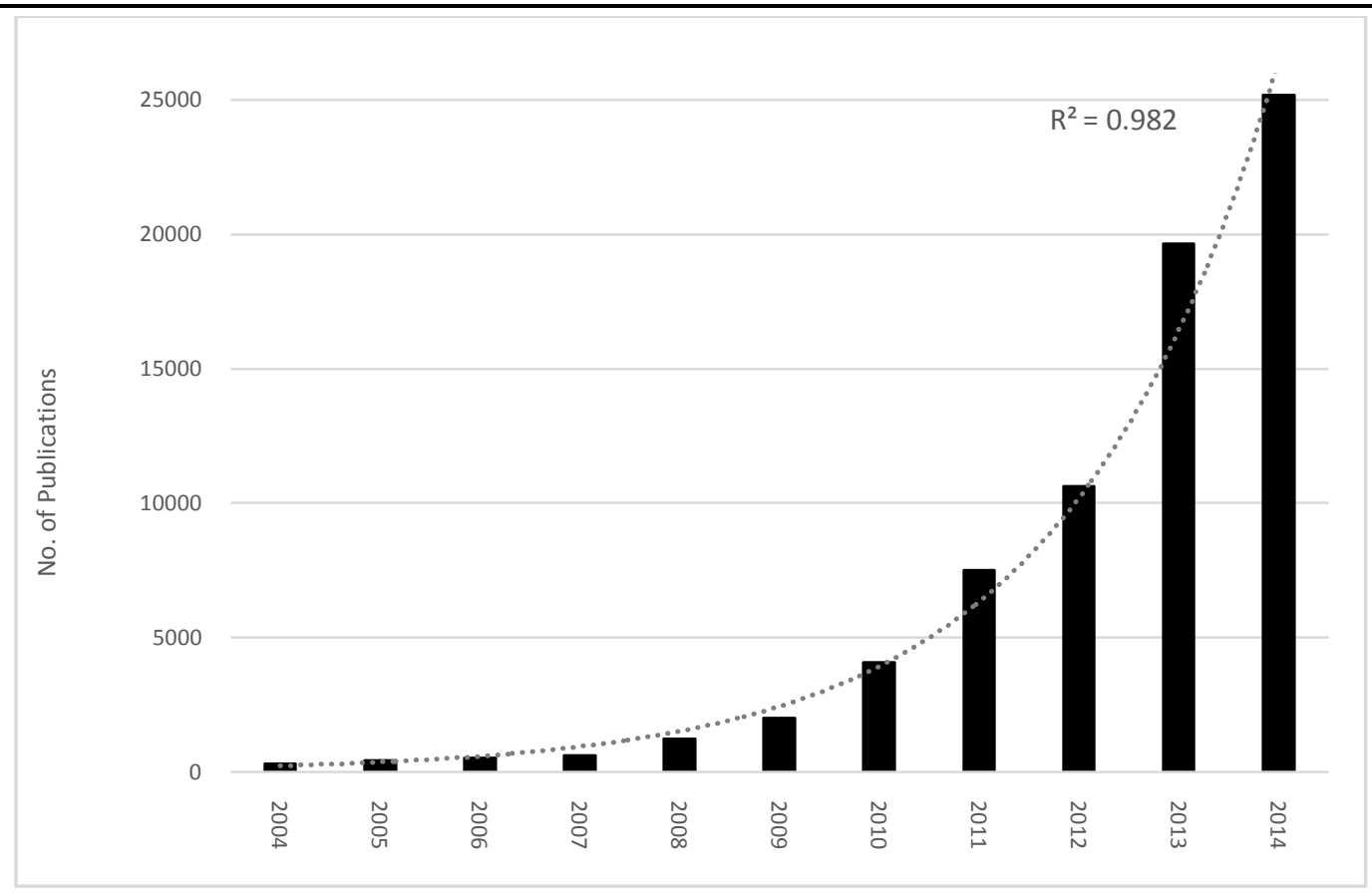

Figure1. Historical Evolution of Biotechnology Scientific Publishing Indexed in Brazil since 2004.

By observing the number of articles published in this period, there is an increase in the scientific publication trends, which indicates an intensive scientific activity over the past ten years, mainly in the last five years, presenting exponential growth with increased production greater than $8,150 \%$, as shown in Figure 1.A probable cause of this growth seems to be the key role that the activities of Biotechnology have gained notoriety on a worldwide scale in recent decades. In Brazil, this increase observed reflects the research government incentives established the financial investments in the area and the implementation of government policies.

Regarding the most frequently used terms to screen the Biotechnology area in Brazil, was possible to find more than 7,000 different terms described by the authors in scientific publications as examples: Vaccine, PCR, DNA, genome, Leishmania, Trypanosoma cruzi, HIV, among others. Some of them were not used as initial descriptors when searching the database.

As for the specific analysis of those terms, it is noted that terms such as PCR and DNA, initially used in searches in the Web of Science database for scientific publications, they are often used since the beginning of the period analyzed, which means that since 2004, these are being associated with Modern Biotechnology Techniques. Other terms such as "Genomic" (68 articles), "Proteomics" (25 articles) and "Stem cell" (21 articles) are further frequent, however, they are related to more advanced future bearing technologies of Modern Biotechnology, being mentioned in Brazil by the National Biotechnology Committee as the frontier areas of Biotechnology. This observed result is associated with the Brazil collaboration in the genome projects as example the mapping of the Xylella fastidiosa genome in 1997, and later, working in international project such as Human Genome Project (HGP) in 1999.

According to reference [8] some areas of Biotechnology will have a major impact in the near future in the development of new technologies and its applications, which are: the Genomics, Transcriptomics, Pharmacogenomics, Bioengineering, Biomaterials and Synthetic Biology. Some themes related to those terms were detected in this dataset. Table 2 presents terms mentioned by authors (keywords' author) with more than 50 citations related to the field of Biotechnology.

From the total of scientific publications found, it can be observed terms like Leishmania, Trypanosoma cruzi, Schistosoma mansoni and Chagas disease, which refer to a potential application. It should be emphasized that the data collected point out that scientific research on Biotechnology in Brazil is directly related to the study of some relevant social problems of a country mainly related to tropical diseases. 
Table2. Terms with more than 50 citations used by authors in the fields Title, Abstract and Keywords in the articles published by Brazil.

\begin{tabular}{|l|l|l|l|l|l|}
\hline Articles & Top Terms (keywords) & Articles & Top Terms (keywords) & Articles & Top Terms (keywords) \\
\hline 330 & vaccine & 91 & cell & 65 & molecularmarker \\
\hline 320 & PCR & 80 & diagnosis & 59 & gene \\
\hline 226 & DNA & 75 & expressed gene & 57 & HIV \\
\hline 163 & genetic & 73 & genotype & 50 & microsatellite \\
\hline 134 & Brazil & 67 & Trypanosoma cruzi & 58 & chromosome \\
\hline 115 & genome & 73 & oxidative stress & 56 & apoptosis \\
\hline 112 & polymorphic & 70 & cytokine & 62 & bovinediseases \\
\hline 121 & Leishmania & 65 & genomics & 49 & cancer \\
\hline 50 & Schistosoma mansoni & 48 & inflammation & 52 & fish \\
\hline 45 & Chagas disease & 50 & epidemiology & 50 & drugs \\
\hline
\end{tabular}

\subsection{Profile of the Scientific Publications in Biotechnology Field}

Biotechnology permeates many areas of knowledge because its intrinsic multidisciplinary characteristics. Therefore, when analyzing the frequency of publication of scientific areas, there is a predominance of Biochemistry \& Molecular Biology (11,98\%), followed by Genetics \& Heredity (10,94\%),Immunology (8,69\%), Microbiology (7,57\%) and Veterinary Science $(6,22 \%)$, together representing $45,40 \%$ of total articles published, respectively. However, this study highlights the wide dispersion of scientific publications by all thematic areas. Figure 2 demonstrates this percentage distribution for all the 20 areas with number of articles greater than 200 indexed in ISI/Web of Science.

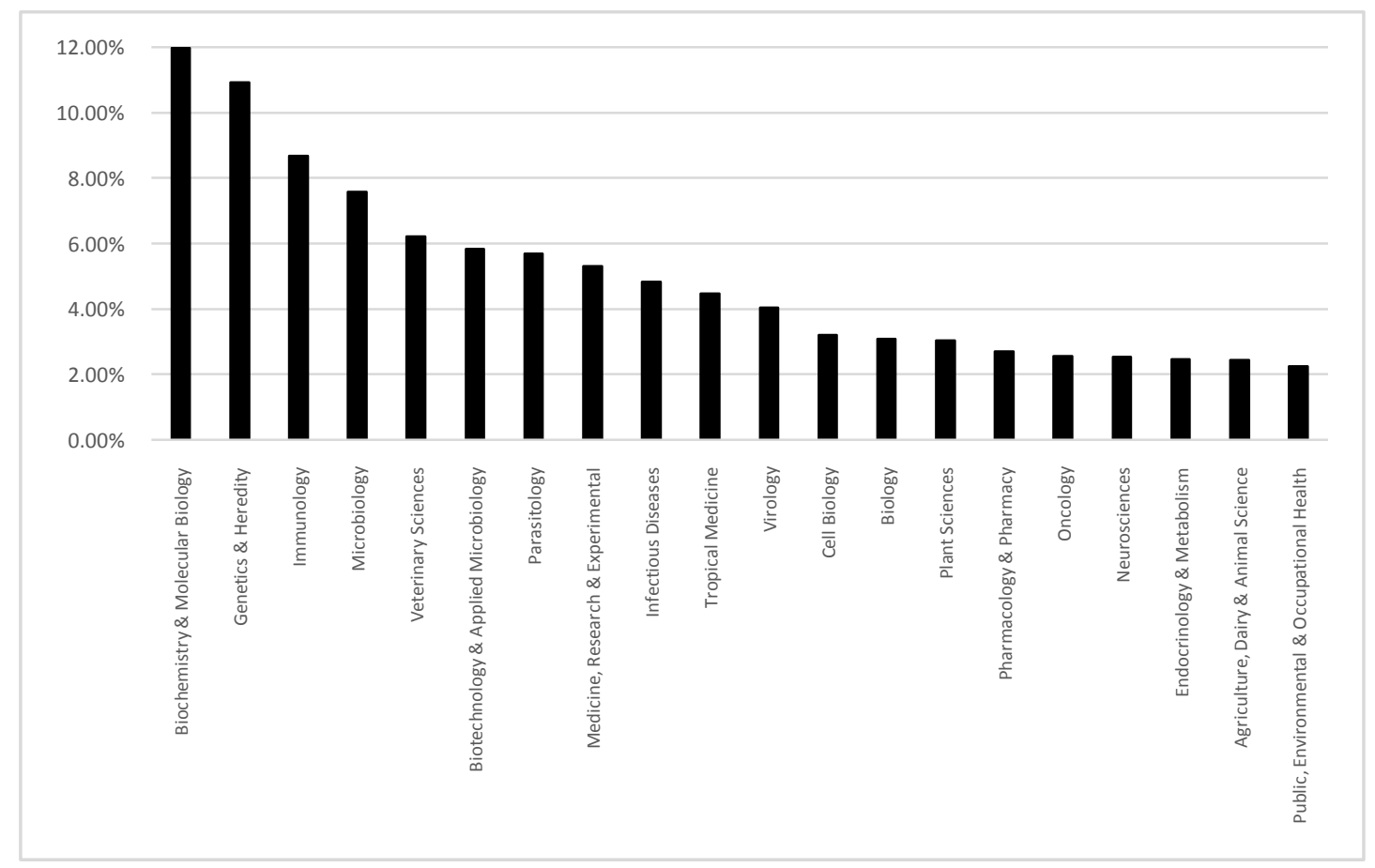

Figure2. Percentage Distribution of Scientific Publications on Biotechnology by Areas of Knowledge indexed on database. Period 2004 to 2014.

It can be observe that most of the articles found is in the areas like Life Sciences and Health, highlighting specific areas such as Molecular Biology, Genetics, Immunology and Microbiology. The predominance of these areas was already expected due to the characteristics of Biotechnology, but it is interesting to note that areas such as Molecular Biology and Genetics have a significant interest towards other traditional areas such as Chemical and Pharmaceutical industries.

Note, also, that a considerable number of articles is classified as multidisciplinary, confirming that research in Biotechnology, as mentioned previously, brings together researchers from different areas of knowledge. This, probably, highlight the increasingly important role of biotechnological techniques for development of new products.

Of the 72,187 articles published in internationally indexed journals it was possible to notice a trend of publication in these two main thematic areas on Health and Life Science. It is noteworthy that these 
thematic areas coincide with the main keywords previously identified. Another aspect to note concerns the regional coverage of the top 20 journals, which means that the majority of Brazilians scientific articles is submitted in Brazilian journals $(60 \%)$, or particularly in indexed American journals $(30 \%)$. This indicator reflects the little dynamics of international cooperation of Brazilian research groups. Among the indexed journals, the Vaccine Journal has the highest number of articles (220), followed by other Journals such as Memórias Instituto Oswaldo Cruz (191) and Genetics and Molecular Biology (184).Table 3 presents the top 20 journals with a number of scientific publications greater than 40 articles.

Table3. Main Internationally Indexed Journals with Biotechnology related Articles.

\begin{tabular}{|l|l|l|l|}
\hline Journal Index & Articles & Journal Index & Articles \\
\hline Vaccine & 220 & PLoSOne & 51 \\
\hline Mem. Inst. Oswaldo Cruz & 191 & J. Clin. Microbiol & 50 \\
\hline Genet. Mol. Biol & 184 & Cienc. Rural & 48 \\
\hline Rev. Bras. Zootecn & 140 & Rev. Soc. Bras. Med. Trop & 45 \\
\hline Genet. Mol. Res & 131 & Pesqui. Agropecu. Bras & 44 \\
\hline Brazilian J. Med. Biol. Res & 128 & Exp. Parasitol & 43 \\
\hline Arq. Bras. Med. Vet. Zootec & 87 & MicrobesInfect & 43 \\
\hline Braz. J. Microbiol & 87 & BMC Genomics & 41 \\
\hline Pesqui. Vet. Bras & 68 & Braz. Arch. Biol. Technol & 41 \\
\hline Infect. Immun & 57 & J. Med. Virol & 40 \\
\hline
\end{tabular}

An interesting fact observed is the leadership position of Vaccine Journal, which justly gives priority an analysis of information and knowledge about human vaccines (infectious diseases and noninfectious diseases) and veterinary vaccines, Molecular Biology, Immunology, Production and manufacturing, Regulatory and Legislation aspects. It is followed by others publications in areas such as Microbiology, Biology, Genetics, Life Sciences and others.

Considering the authors' affiliation, it was observed that there are 441 institutions, showing a high dispersion among the authors' institutions in Brazil. It's important to highlight the significant number of articles produced by institutions such as the University of São Paulo (USP) representing 32,71\%, followed by the Oswaldo Cruz Foundation (FIOCRUZ) with 8,92\% and the Federal University of Rio Grande do Sul (UFRGS) with 7,58\% articles, respectively. Another significant aspect to be observed is the predominance of public governmental institutions such as universities or research centers, revealing a concentration of activities in Biotechnology by public institutions or nonprofits corporations in both academic and investigative levels. Figure 3 shows the top 20 institutions that have published more than 100 articles in the observed period.

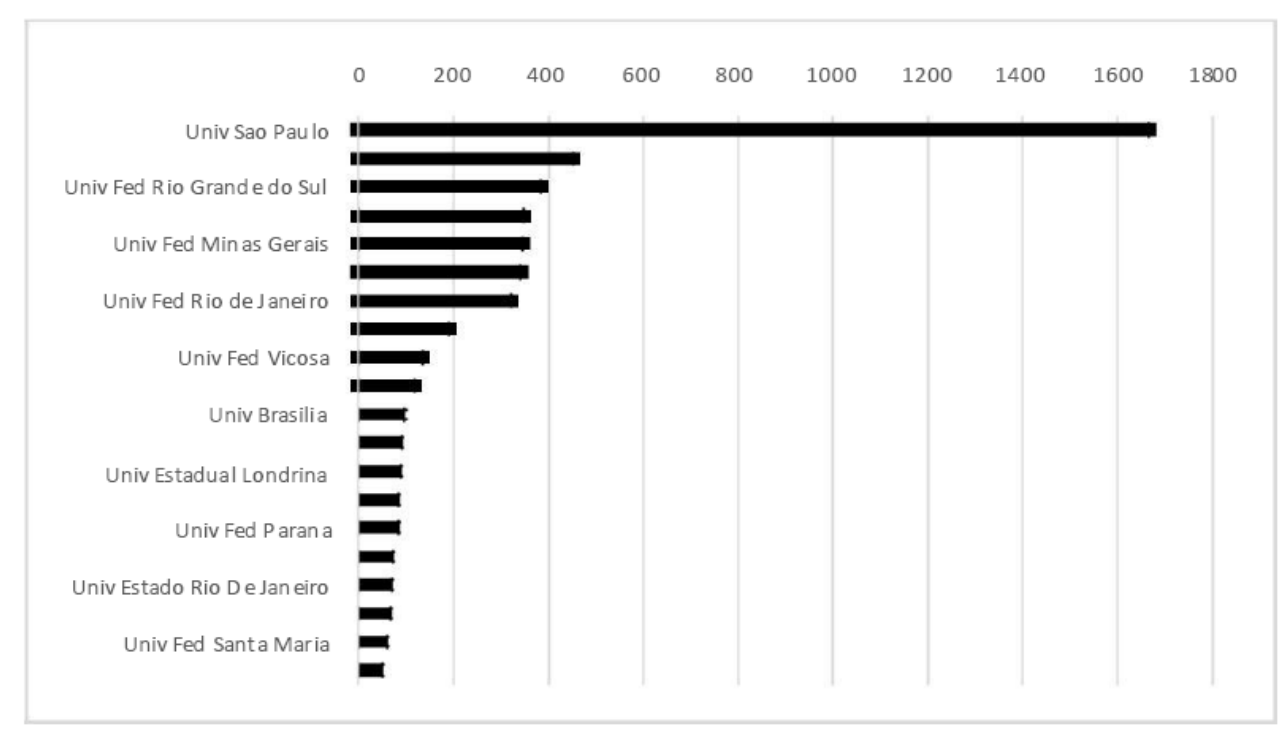

Figure3. Leading Brazilian institutions with major publications in Biotechnology for the period 2004 -2014.

The research results presents that the most of institutions is located in South/Southeast regions, which are more developed regions of the country. There is little representation of institutions in the CenterWest/ Northwest regions, presented only in the Figure 3 by the following universities: University of Brasília, Federal University of Pernambuco, University of Goiás and Federal University of Ceará. 
In addition, there is the significant presence of the public universities of São Paulo (USP, UNESP and UNICAMP), which together account for a significant share of national scientific output in the Biotechnology area, ie $46.31 \%$ of published articles in journals are from USP. This observed result was expected because since the beginning of projects development in Biotechnology area (Xylella fastidiosa genome and HGP/Brazil), there was an intensive participation of research groups of these universities. Furthermore, we can mention the continuous financial support from FAPESP Foundation to development projects in the areas such Biotechnology and Bioprospection.

\subsection{Maps of Knowledge and International Partnership}

Regarding the analysis of relationships between composing agents of the Organizational System of Science, Technology and Innovation within a country, many authors refer to the central idea of networking and the valuable interactions between system components and its main actors: institutions, organizations and individuals in order to promote the dissemination and use of new scientific knowledge [9].

In accordance with this premises, we sought to observe how these actors relate to each other using the number of publications of scientific cooperation between institutions and between countries, which means an analysis of the links established between the organizations; on a macro level, the international relationships developed by these institutions of $R \& D$. The best representation of these collaborations is the visualization of maps of knowledge where the existence or not of correlations and the degree of its intensity is clear, which provide to decision-makers some strategic subsidies in future planning of national activities of ST\&I.

Regarding the network map of articles' authorship in Brazil, for the Biotechnology area, it is possible to identify an intensive collaboration between different institutions, especially among Brazilian institutions, showing the will to develop endogenous capacity of Brazilian groups to perform work and publish papers with little support from international cooperation.

It is possible to note groups with strong collaboration such as the University of São Paulo (USP), Federal University of Rio de Janeiro (UFRJ), the University of Campinas (UNICAMP) and Oswaldo Cruz Foundation (FIOCRUZ). These collaborations between Brazilian institutions demonstrate that relationship are based more heavily on the model of interaction between universities, research centers and non-governmental research centers and of little interaction with companies. It should be emphasized that this scenario will change since the implementation of the Organic Law of Science, Technology and Innovation in January 2016, where the enterprise sector was encouraged to invest more in internal activities of ST\&I and/or in partnerships with public institutions, aiming to promote alliances between universities and scientific research center with the private sector [10]. Figure 4 shows the collaboration network among institutions with more than 60 articles published.

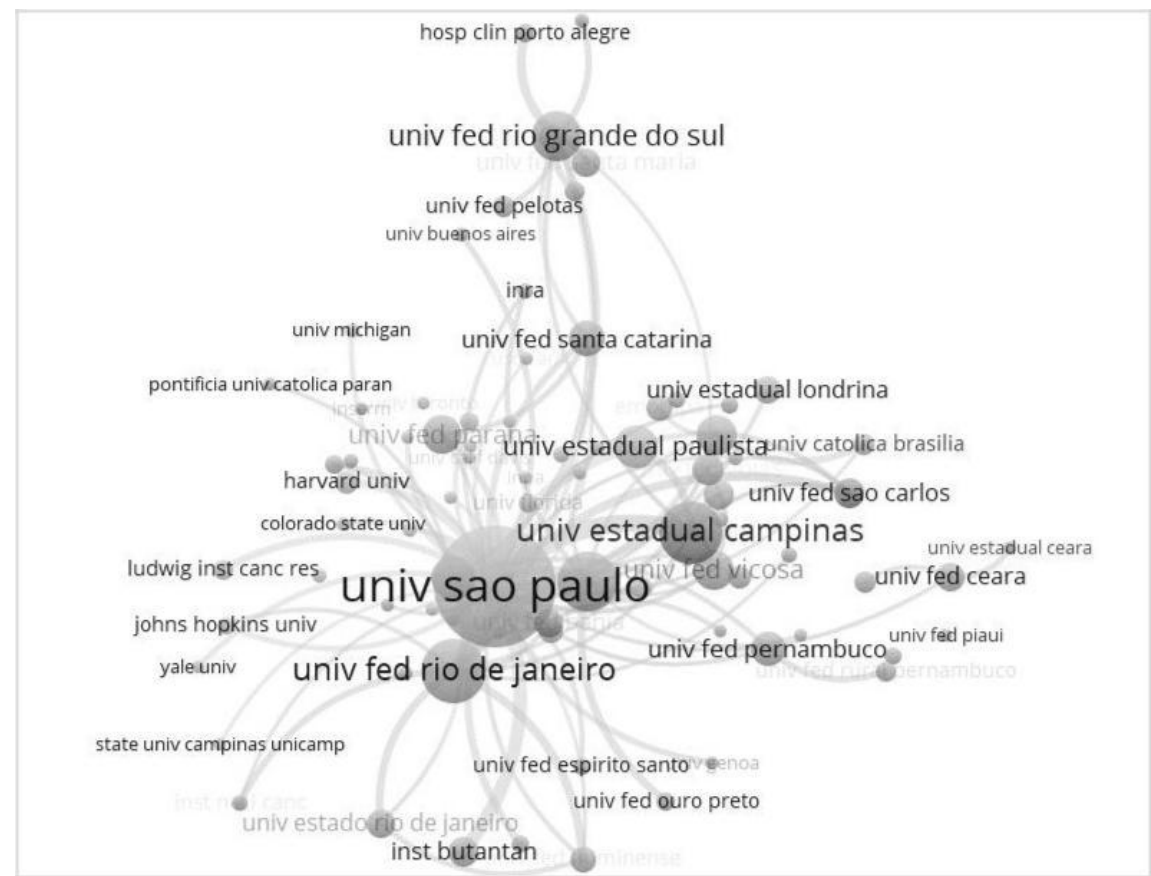

Figure4. Map of Institutional Relations on Biotechnology for Brazil./ Source: Map presentation software VOSviewer ${ }^{\circledR}$. 
From a macro perspective, there is a large international collaboration, particularly with five countries: The United States (12.71\%), UK (2.25\%), France (2.18\%), Germany (1.34\%) and Spain (1.25\%). Figure 5 shows the map collaboration network among 40 major countries and Brazil in Biotechnology area.

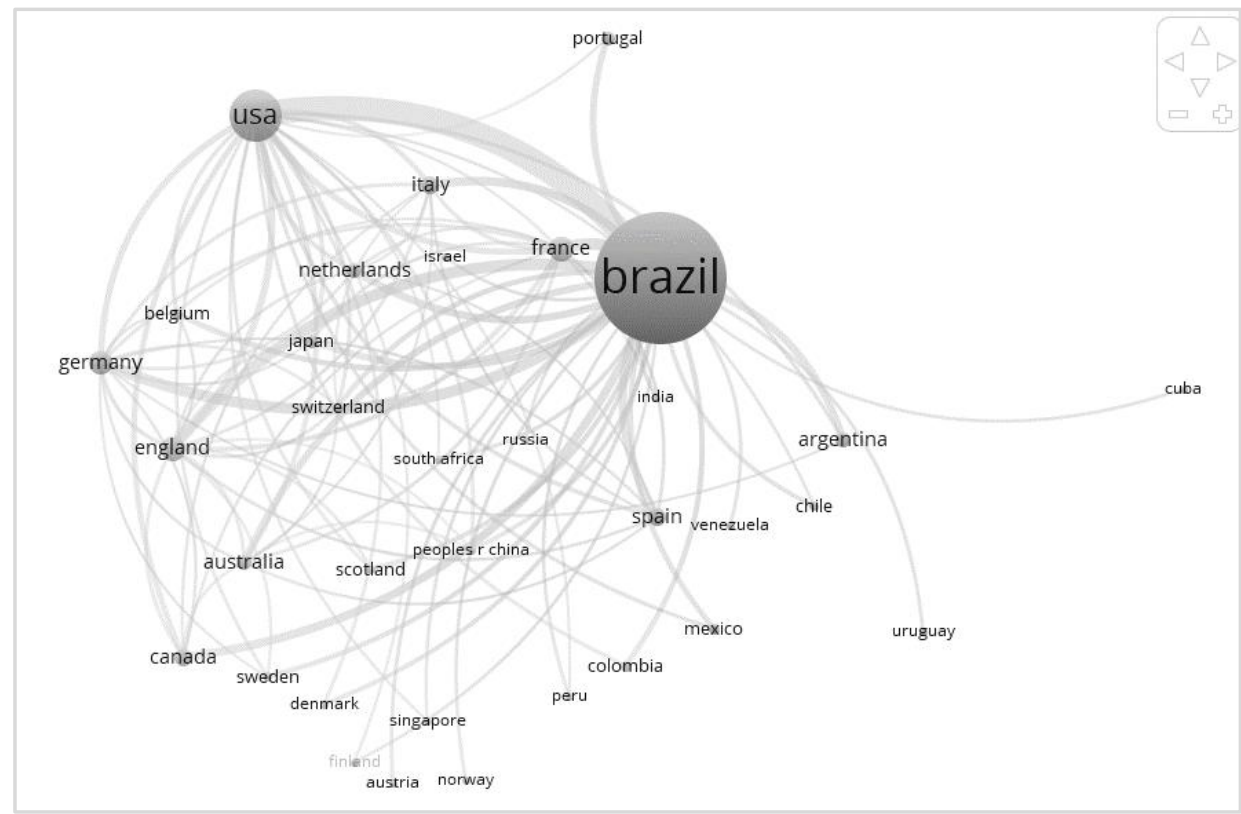

Figure5. Map of network based on a co-authorship between Brazil and the 40 Major Countries, on Biotechnology area. Source: Map presentation software VOSviewer ${ }^{\circledR}$

\section{Conclusions}

By tradition Biotechnology is a technology that is deeply dependent on the studies of the basic research area. Its success in any country is tightly related to government policies regarding the promotion of science and its technological diffusion. This paper presented the growing momentum of scientific research of Biotechnology in Brazil, with a higher growth of 8,150\%, in 10 years, over the number of scientific articles published in the area, especially in the last five years.

With respect to searched terms, "Vaccine", "PCR" and "DNA" are among the terms most frequently used, being cited by the authors as Keywords in scientific journals since 2004 as well as in main journals such as Vaccine and Mem Inst Oswaldo Cruz. It is noteworthy that terms related to the frontier area of knowledge have also appeared in this research such as Proteomics and Stem cells, signaling that the scientific research in this area in Brazil are consistent with trends worldwide. A wide dispersion in relation to the thematic areas of Biotechnology is observed, however, concentrated mainly in areas such as Biochemistry \& Molecular Biology and Genetic \& Heredity. Three Institutions are highlighted here: São Paulo University (USP), Oswaldo Cruz Foundation (FIOCRUZ) and Federal University of Rio Grande do Sul (UFRGS). It is worth noting that institutions that fulfill scientific research in this area

Regarding analysis of relationships between agents that compose the Organizational System of Science, Technology and Innovation in a country, it was found that for Biotechnology, there is a large network of collaboration among national and international institutions, as well as networking among various countries that present a positive factor in the Biotechnological development of a country. Finally, we identified from macro perspective the U.S. as a major co-author of scientific publications relating the subject, followed by United Kington and France.

\section{REFERENCES}

[1] Antunes AMS, Canongia C, Bahrut E, Rodrigues HT, Pio M, Gianinne R. Prospección tecnológica: gestión del conocimiento y Inteligencia Competitiva: Modelos de Gestión para la Toma de Decisiones y Construcción de Futuro. In: Sinergía entre la Prospectiva Tecnológica y la vigilancia Tecnológica Y Inteligencia Competitiva. ${ }^{\text {st }}$. Ed. Colciencias, 2008. p. 49-83.

[2] Gertler MS, Yael ML. Local nodes in global networks: The geography of knowledge flows in biotechnology innovation. Industry and Innovation. 2005, 12, 487-507. [Available from: http://digitalcommons.ilr.cornell.edu/articles/122] 
[3] Ministério do Desenvolvimento, Indústria e Comércio Exterior. Diretrizes de política industrial, tecnológica e de comércio exterior. Brasília.2003. [Available from: http://www.anped11.uerj.br/ diretrizes.pdf] [Accessed: 2004-04-20].

[4] Silveira J, Borges I. Um panorama da biotecnologia moderna. In: Silveira J, Poz M, Assad A. editors. Biotecnologia e recursos genéticos: desafios e oportunidades para o Brasil. 1st Ed. Unicamp, Instituto de Economia, 2004. 412p. ISBN: 85871200509788587120052

[5] Lima RA, Velho LML, Faria LIL. Delimitação de uma área multidisciplinar para análise bibliométrica de produção científica: o caso da Bioprospecção. Revista Transformação, Campinas, 19 (2): 153-168, maio/ago, 2007. DOI: 10.1590/S0103-37862007000200006.

[6] Santana MFE, Martínez RG, Pereira Jr. N, Antunes AMS. Knowledge Management and Analysis of Scientific Biotechnology Trends in Venezuela. Journal of Technology Management \& Innovation, 7 (1): 145-158, 2012. DOI: 10.4067/S0718-27242012000100010.

[7] Van Eck, NJ, Waltman, L, Software survey: VOSviewer, a computer program for bibliometric mapping”. Scientometrics. 2010. 84 (2), 523-538. DOI:10.1007/s11192-009-0146-3

[8] Krattiger, A.F. Public-private Partnerships for Efficient Proprietary Biotech Management and Transfer, and Increase Private Sector Investments. In: A Briefing Paper with Six Proposals commissioned by UNIDO. IP Strategy Today, No. 4, p. 42, 2002. [Available from: www.biodevelopments.org/ip/index.htm]. [Accessed: 2012-12-15]

[9] Freeman C. Technology Policy and Economic Performance. Lessons from Japan, London and NY. Research Policy. 2002, 17 (5): 309-3010, 1988. DOI: 10.1016/0048-7333(88)90011-X.

[10] Presidência da República. Casa Civil. LEI No 13.243. De January, $11^{\text {st }}$ 2016.Marco Legal da Ciência, Tecnologia e Inovação no Brasil.

\section{AUTHORS' BIOGRAPHY}

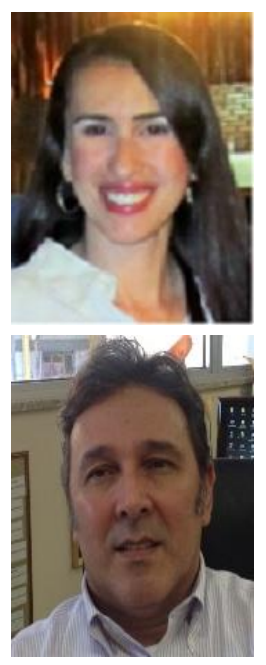

Maria de Fátima Ebole Santana, Research associate (EPSJV/Fiocruz). Dr.Student of Foresight and Knowledge Management (EQ/UFRJ), MSc. Management \& Innovation Technology (EQ/UFRJ, 2004), BSc. Chemical Engineer (EQ/UFRJ, 2002).

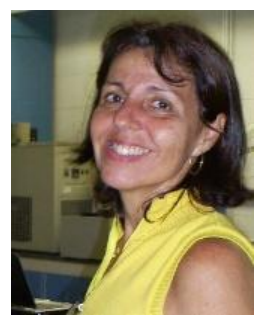

Adelaide Maria de Souza Antunes, Senior Especialist (INPI). Professor (EQ/UFRJ). Post-doctoral (IFP, 1989). Dr. Chemical Engineering (COPPE/UFRJ, 1987). MSc. Chemical Engineering (COPPE/UFRJ, 1979). ChemicalEngineer (EQ/ UFRJ, 1976).

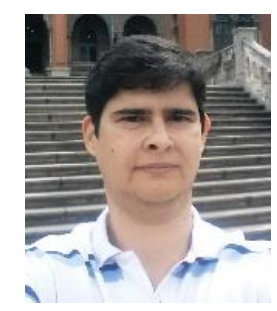

Marcio Sacramento de Oliveira, Research(EPSJV/Fiocruz). Dr. Public Health and Environment (ENSP/Fiocruz, 2011).MSc. Parasitic Biology (IOC/Fiocruz, 2004). Bsc. Biology (Unigranrio, 2000). 